\title{
Independent Roles of Monocyte Chemoattractant Protein-1, Regulated on Activation, Normal T-Cell Expressed and Secreted and Fractalkine in the Vulnerability of Coronary Atherosclerotic Plaques
}

\author{
Jifu Li, MD; Yuan Guo, MD, PhD; Xiaorong Luan, BSc; Tianjun Qi, BSc; Daqing Li, MD, PhD; \\ Yuguo Chen, MD, PhD; Xiaoping Ji, MD, PhD; Yun Zhang, MD, PhD; Wenqiang Chen, MD, PhD
}

\begin{abstract}
Background: Monocyte chemotactic factors contribute to the formation of atherosclerotic plaques. The present study aimed to elucidate the roles of monocyte chemoattractant protein-1 (MCP-1), Regulated on Activation, Normal T-cell Expressed and Secreted (RANTES) and fractalkine on the vulnerability of atherosclerotic plaques in patients with acute myocardial infarction (AMI) or unstable angina pectoris (UAP).

Methods and Results: Sixty patients with AMI, 60 patients with UAP, 60 patients with stable angina pectoris (SAP) and 40 patients without coronary heart disease comprised the study group. Quantitative coronary angiography and intravascular ultrasound (IVUS) were performed. Concentrations and mRNA expression levels of high-sensitivity C-reactive protein, MCP-1, RANTES and fractalkine were measured by ELISA and RT-PCR, respectively. IVUS found that $51.3 \%$ of the AMI patients and $47.7 \%$ of the UAP patients had soft lipid plaques. Among the SAP patients, $52.4 \%$ had fibrous plaques and only $17.1 \%$ had soft plaques. AMI and UAP patients had larger plaque burden and vascular remodeling index than did the SAP patients $(P<0.01)$. The averaged number of migrated monocytes was higher in AMI and UAP patients. Concentrations and mRNA expression levels of MCP-1, RANTES and fractalkine were significantly higher in AMI and UAP patients than in SAP patients $(P<0.05-0.01)$. The plaque burden in UAP patients as measured with IVUS correlated well with monocytes chemotaxis $(r=0.56, P<0.01)$.
\end{abstract}

Conclusions: MCP-1, RANTES and fractalkine independently participate in the pathogenesis of plaque vulnerability and subsequent plaque rupture. (Circ $J$ 2012; 76: 2167-2173)

Key Words: Acute coronary syndrome; Atherosclerosis; Monocyte chemotactic factors; Vulnerable plaque

$\mathbf{V}$ ulnerable atherosclerotic plaque is a major pathological lesion leading to plaque rupture and thrombosis in patients with acute coronary syndrome (ACS). 1,2 Studies have demonstrated that atherosclerosis is a complex and perpetuating inflammatory disease and active inflammation is an important feature of vulnerable plaques. Monocyte infiltration of the arterial intima is essential for inflammation and contributes to the formation of atherosclerotic plaques. Leukocyte migration from blood into tissues is controlled by endothelial leukocyte adhesion molecules and multiple chemokines.

Chemokines constitute a family of structurally related and secretable basic chemotactic cytokines in both human and ex- perimental atherosclerotic disease. Chemokines are classified into 4 subgroups (CXC, CC, C, CX3C) according to the position of the $\mathrm{N}$-terminal cysteines. ${ }^{3-5}$ As the first and prototypic CC chemokine, monocyte chemoattractant protein-1 (MCP-1) has high expression in human atherosclerotic lesions and in animal models of atherosclerosis with dietary-induced hypercholesterolemia. The intensive infiltration of macrophages into plaques with active inflammation could be, to a large extent, due to the chemotactic effects of MCP-1. ${ }^{6-8}$ Regulated on Activation, Normal T-cell Expressed and Secreted (RANTES) also belongs to CC family of chemokines, and studies in humans and murine models of atherosclerosis demonstrate a central role

Received December 15, 2011; revised manuscript received April 10, 2012; accepted April 27, 2012; released online June 5, 2012 Time for primary review: 21 days

The Key Laboratory of Cardiovascular Remodeling and Function Research, Chinese Ministry of Education and Chinese Ministry of Health, Shandong University Qilu Hospital, Jinan, Shandong (J.L., Y.G., X.L., T.Q., D.L., Y.C., X.J., Y.Z., W.C.); Department of Cardiology, The Affiliated Hospital of Zibo Coal Berual, Zibo (T.Q.), PR China

The first four authors contributed equally to this work (J.L., Y.G., X.L., T.Q.).

Mailing address: Yun Zhang, MD, PhD or Wenqiang Chen, MD, PhD, The Key Laboratory of Cardiovascular Remodeling and Function Research, Chinese Ministry of Education and Chinese Ministry of Health, Shandong University Qilu Hospital, Jinan, No.107, Wen

Hua Xi Road, Jinan, Shandong, 250012, P.R. China. E-mail: zhangyun@sdu.edu.cn or chenwenqiang33@sina.com

ISSN-1346-9843 doi:10.1253/circj.CJ-11-1457

All rights are reserved to the Japanese Circulation Society. For permissions, please e-mail: cj@j-circ.or.jp 


\begin{tabular}{|c|c|c|c|c|}
\hline Parameter & Gr AMI $(n=60)$ & UAP $(n=60)$ & Gr SAP $(n=60)$ & Control $(n=40)$ \\
\hline Age (years) & $55.4 \pm 5.3$ & $57.9 \pm 7.2$ & $57.3 \pm 5.7$ & $57.0 \pm 7.1$ \\
\hline Male & 39 & 33 & 35 & 37 \\
\hline Systolic BP (mmHg) & $139.4 \pm 11.9$ & $136.0 \pm 11.1$ & $136.7 \pm 12.3$ & $130.1 \pm 9.2$ \\
\hline Diastolic BP (mmHg) & $82.3 \pm 12.7$ & $80.1 \pm 12.5$ & $81.2 \pm 15.0$ & $78.4 \pm 9.9$ \\
\hline $\mathrm{BMI}\left(\mathrm{kg} / \mathrm{m}^{2}\right)$ & $27.6 \pm 3.1$ & $26.9 \pm 2.5$ & $27.1 \pm 2.7$ & $25.0 \pm 2.2$ \\
\hline Diabetes mellitus & $23(38.3 \%)$ & $18(30.0 \%)$ & $16(26.7 \%)$ & $10(25.0 \%)$ \\
\hline Dyslipidemia & $26(43.3 \%)$ & $20(33.3 \%)$ & $19(31.7 \%)$ & $12(30.0 \%)$ \\
\hline Hypertension & $22(36.7 \%)$ & $19(31.7 \%)$ & $18(30.0 \%)$ & $11(27.5 \%)$ \\
\hline Current smoker & $21(35.0 \%)$ & $21(35.0 \%)$ & $20(33.3 \%)$ & $12(30.0 \%)$ \\
\hline Glucose (mg/dl) & $115.0 \pm 31.0$ & $116.1 \pm 36.5$ & $114.7 \pm 30.2$ & $103.3 \pm 23.0$ \\
\hline Total cholesterol (mg/dl) & $226.6 \pm 31.3$ & $229.3 \pm 38.7$ & $213.5 \pm 38.3$ & $211.6 \pm 29.8$ \\
\hline LDL (mg/dl) & $151.2 \pm 34.0$ & $155.1 \pm 37.5$ & $133.0 \pm 33.6$ & $130.7 \pm 22.4$ \\
\hline HDL (mg/dl) & $40.2 \pm 5.8$ & $41.0 \pm 6.2$ & $39.2 \pm 5.4$ & $42.9 \pm 8.9$ \\
\hline Triglycerides (mg/dl) & $139.1 \pm 54.0$ & $142.6 \pm 54.9$ & $140.8 \pm 57.6$ & $137.3 \pm 50.5$ \\
\hline Leucocytes (×109/L) & $8.2 \pm 3.1^{*}, \dagger$ & $8.0 \pm 3.0^{*}, \dagger$ & $5.2 \pm 2.2$ & $4.9 \pm 2.0$ \\
\hline hsCRP (mg/L) & $6.9 \pm 2.7^{\star \star, t \dagger}$ & $5.7 \pm 2.3^{\star \star,+\dagger}$ & $2.9 \pm 1.2$ & $2.7 \pm 1.4$ \\
\hline MCP-1 (pg/ml) & $91.2 \pm 9.7^{* *,+\dagger}$ & $87.3 \pm 9.1^{* *,+\dagger}$ & $37.0 \pm 6.6^{\dagger}$ & $23.7 \pm 7.1$ \\
\hline RANTES (pg/ml) & $62.7 \pm 8.2^{*,+\dagger}$ & $61.8 \pm 7.9^{*},+\dagger$ & $27.3 \pm 4.5^{\dagger}$ & $15.8 \pm 5.1$ \\
\hline Fractalkine (pg/ml) & $65.1 \pm 9.7^{*,+t}$ & $62.3 \pm 10.5^{\star},+\dagger$ & $34.0 \pm 4.7^{\dagger}$ & $19.9 \pm 6.0$ \\
\hline
\end{tabular}

${ }^{*} \mathrm{P}<0.05,{ }^{* *} \mathrm{P}<0.01$ vs. $\mathrm{SAP} ; \mathrm{t} \mathrm{P}<0.05, \mathrm{tt} \mathrm{P}<0.01$ vs. Control.

AMI, acute myocardial infarction; UAP, unstable angina pectoris; SAP, stable angina pectoris; $\mathrm{BP}$, blood pressure;

BMI, body mass index; LDL, low-density lipoprotein; HDL, high-density lipoprotein; hsCRP, high-sensitivity C-reac-

tive protein; MCP, monocyte chemoattractant protein-1; RANTES, Regulated on Activation, Normal T-cell Expressed and Secreted.

\begin{tabular}{|cc|}
\hline $\begin{array}{c}\text { Table 2. Primers } \\
\text { Gene } \\
\text {-actin }\end{array}$ & \multicolumn{1}{c|}{ Primer sequence } \\
& F:5' CATGTACGTTGCTATCCAGGC 3' \\
MCP-1 & R:5' CTCCTTAATGTCACGCACGAT 3' \\
& F:5' CAGCCAGATGCAATCAATGCC 3' \\
RANTES & R:5' TGGAATCCTGAACCCACTTCT 3' \\
& F:5' ATCCTCATTGCTACTGCCCTC 3' \\
Fractalkine & R:5' GCCACTGGTGTAGAAATACTCC 3' \\
& R:5' CTCCACGGTGTGACGAAATG 3' \\
&
\end{tabular}

RT-PCR, reverse transcription polymerase chain reaction. Other abbreviations as in Table 1.

of RANTES in the initiation of atherosclerotic plaque and in promoting late-stage atherosclerosis. ${ }^{9}, 10$ Fractalkine (CX3CL1) is a unique member of the CX3C subfamily and is expressed in both a soluble and membrane-bound form on the surface of the inflamed endothelium. ${ }^{11,12}$ Combadière et al found that the CX3CR1-CX3CL1 pathway plays a direct and major role in the development of macrophage-rich atherosclerotic lesions and that CX3CR1/apolipoprotein E double knockout mice show decreased atherosclerotic lesion formation. ${ }^{13}$ Fractalkine is reportedly associated with atherogenesis and 2 specific mutations of the CX3CR1 gene have been shown to reduce the risk for future coronary events. ${ }^{14}$ However, whether MCP-1, RANTES and fractalkine prompt plaque vulnerability and contribute to ACS is still unknown. In the present study, we assessed the hypothesis that the expression of MCP-1, RANTES and fractalkine is higher in patients with acute myocardial infarction (AMI) or unstable angina pectoris (UAP) and is closely associated with plaque vulnerability.

\section{Methods}

\section{Study Population}

All 220 patients underwent selective coronary angiography (CAG; 127 men, 93 women; age 59.8 \pm 8.2 years, range $38-84$ years) and were divided into 4 groups according to the guidelines of the American College of Cardiology and American Heart Association. ${ }^{15,16}$ Group A comprised 60 patients with AMI and group B included 60 patients with UAP. There were 60 patients with stable angina pectoris (SAP) in group $\mathrm{C}$ and 40 patients without coronary heart disease in group $\mathrm{D}$ (control group). The baseline characteristics of the 4 groups are shown in Table 1 . All patients in the AMI, UAP and SAP groups were treated after admission with antiplatelet and other therapies including angiotensin-converting enzyme inhibitors/angiotensin II receptor blockers, $\beta$-blockers and statins. All patients gave their informed consent to this study and the protocol was approved by the Ethics Committee of Qilu Hospital of Shandong University.

\section{Blood Biomarker Measurements}

Blood samples from every patient were collected on admission to hospital. Serum levels of total cholesterol, triglycerides, highdensity lipoprotein cholesterol and low-density lipoprotein cholesterol were measured by enzymatic assays. The C-reactive protein level (CRP) was assayed using a highly sensitive enzyme-linked immunosorbent assay kit (Diagnostic System Laboratory, Chicago, IL, USA). Levels of MCP-1, RANTES and fractalkine were measured using enzyme-linked immunosorbent assay kits (You er Biochemistry Company, Wuhan, China).

\section{Quantitative CAG (QCA)}

All patients underwent CAG. Percent diameter stenosis, percent area stenosis, culprit lesion length, and reference diameter were assessed by QCA, which was performed using the Digital Cardiac Imaging system. Coronary stenosis was defined if 


\begin{tabular}{|c|c|c|c|}
\hline Parameter & Gr AMI $(n=60)$ & UAP $(n=60)$ & $\operatorname{Gr} \operatorname{SAP}(n=60)$ \\
\hline Plaque & 117 & 111 & 105 \\
\hline Lipid plaque & $60(51.3 \%)^{\star \star}$ & $53(47.7 \%)^{\star *}$ & $18(17.1 \%)$ \\
\hline Fibrous plaque & $21(17.9 \%)^{\star \star}$ & $23(20.7 \%)^{\star *}$ & $55(52.4 \%)$ \\
\hline Mixed plaque & $19(16.2 \%)$ & $15(13.5 \%)$ & $13(12.4 \%)$ \\
\hline Calcified plaque & $18(15.4 \%)$ & $19(17.1 \%)$ & $18(17.1 \%)$ \\
\hline Patients with ruptured plaque & $81(69.2 \%)^{\star \star}$ & $59(53.2 \%)^{\star *}$ & $27(25.7 \%)$ \\
\hline Minimum lumen area $\left(\mathrm{mm}^{2}\right)$ & $3.3 \pm 0.9$ & $3.3 \pm 0.8$ & $3.8 \pm 0.9$ \\
\hline External elastic membrane area $\left(\mathrm{mm}^{2}\right)$ & $12.8 \pm 1.3^{\star \star}$ & $12.6 \pm 1.8^{\star \star}$ & $11.4 \pm 1.3$ \\
\hline Plaque area $\left(\mathrm{mm}^{2}\right)$ & $9.5 \pm 2.6^{\star *}$ & $9.3 \pm 2.0^{* *}$ & $7.6 \pm 2.8$ \\
\hline Plaque burden (\%) & $74.2 \pm 10.3^{\star *}$ & $73.8 \pm 8.9^{\star \star}$ & $66.7 \pm 8.3$ \\
\hline Eccentric index & $0.7 \pm 0.2^{*}$ & $0.6 \pm 0.2^{*}$ & $0.5 \pm 0.2$ \\
\hline Remodeling index & $1.1 \pm 0.1^{* *}$ & $1.1 \pm 0.1^{\star *}$ & $1.0 \pm 0.1$ \\
\hline
\end{tabular}

${ }^{*} \mathrm{P}<0.05,{ }^{*} \mathrm{P}<0.01$ vs. SAP.

AMI, acute myocardial infarction; SAP, stable angina pectoris; UAP, unstable angina pectoris.

A

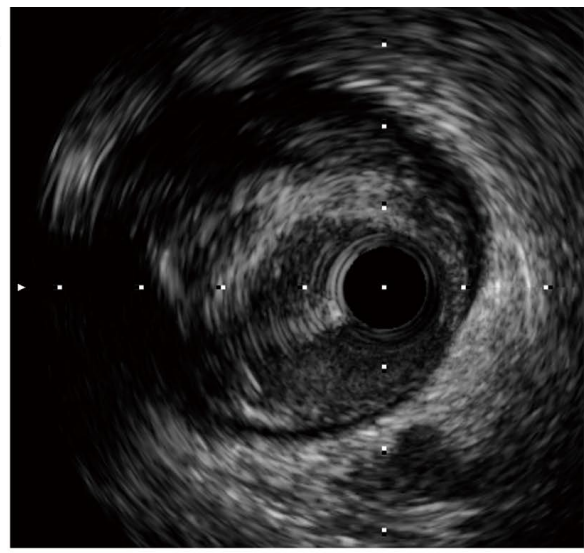

B

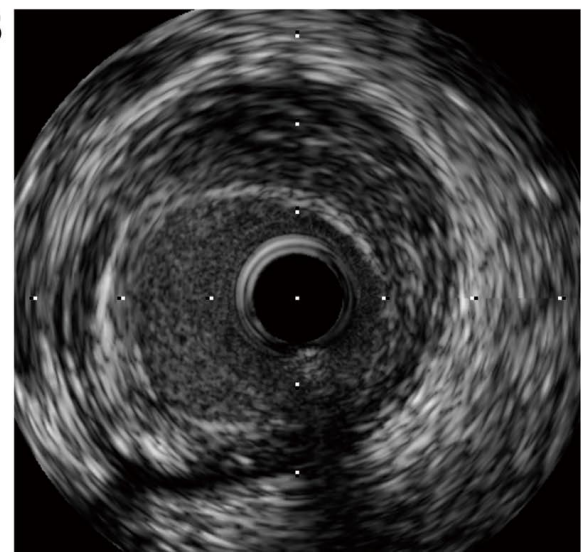

C

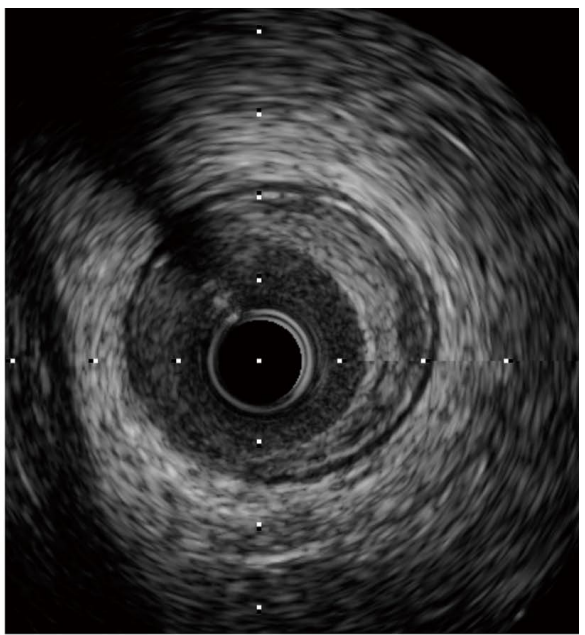

Figure 1. Intravascular ultrasound imaging of the coronary arteries. (A) Plaque with a large lipid core in the coronary artery of a patient with acute myocardial infarction. (B) Lipid plaque in the coronary artery of a patient with unstable angina. (C) Fibrous plaque in the coronary artery of a patient with stable angina.

there was a more than $50 \%$ decrease in diameter compared with an adjacent reference segment and the number of stenotic lesions in each coronary artery was recorded.

\section{Intravascular Ultrasound (IVUS) Studies}

Three-coronary IVUS (iLab, Boston Scientific Corporation,
USA) was carried out in all patients as described previously and the following parameters were measured: external elastic membrane area (EEMA), minimum lumen area, plaque area (PA), plaque burden (PB), plaque eccentricity index, and remodeling index (RI). RI >1.05 was regarded as positive remodeling, $0.95-1.05$ as intermediate remodeling, and $<0.95$ as 

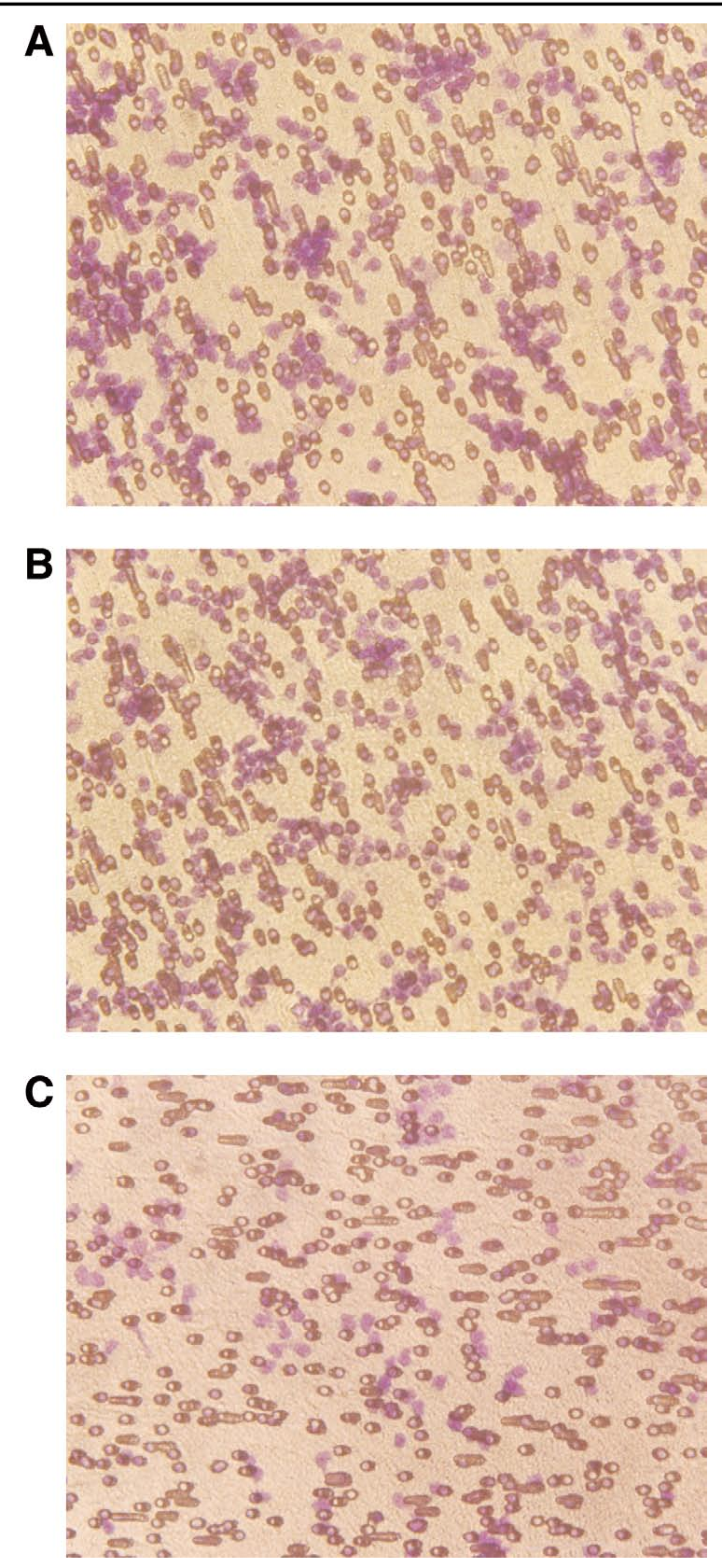

Figure 2. Chemotaxis test. (A) Migrated monocytes in a patient with acute myocardial infarction. (B) Migrated monocytes abound in a patient with unstable angina. (C) Migrated monocytes are rare in a patient with stable angina.

negative remodeling. Coronary plaque composition was assessed visually according to plaque echogenicity. ${ }^{17,18}$ Plaque rupture was defined as a plaque containing a cavity that communicated with the lumen and had an overlying residual fibrous cap fragment or was wedged by newly-formed thrombus, no matter whether plaque rupture occurred in culprit or non-culprit lesions. ${ }^{19}$ The IVUS images were reviewed by 2 independent observers and the final consensus values were used for data analysis.

\section{Chemotaxis Test}

Monocytes were extracted by centrifugation of the blood sam- ples, and $0.1 \mathrm{ml}$ of the monocyte suspension $\left(4 \times 10^{4} / \mathrm{ml}\right)$ was instilled into the transwell chamber to assay monocyte chemotaxis. Monocytes were stimulated by the patient's own serum as described previously. ${ }^{20} \mathrm{Next}$, the number of migrated monocytes and the distance traveled by monocytes in 10 high-power microscopic fields were measured and the values averaged.

\section{Molecular Biological Studies}

Total RNA of the monocytes was extracted, and the mRNA expression of MCP-1, RANTES and fractalkine was examined by quantitative reverse transcription polymerase chain reaction (RT-PCR) using a LightCycler (Roche Applied Science, USA) following the manufacturer's instructions. The mRNA sequences were obtained from GenBank (Table 2). Quantitative values were obtained from the threshold cycle value $(\mathrm{Ct}){ }^{21}$ The transcript number of glyceraldehyde 3-phosphate dehydrogenase was quantified as an internal control. The results of RTPCR were confirmed by gel electrophoresis.

\section{Statistical Analysis}

All statistical analyses were performed with SPSS16.0 software package (SPSS Inc, Chicago, IL, USA). Values are expressed as mean \pm SD. Comparison of continuous variables among multiple groups was performed by analysis of variance with ANOVA and post hoc comparisons were made using the lysergic acid diethylamide test. Chi-squared analysis was applied to compare categorical data. Linear regression analyses were performed to evaluate the relationship between the results of IVUS and chemotaxis and expression of MCP-1, RANTES and fractalkine. A 2-tailed $\mathrm{P}<0.05$ was considered statistically significant.

\section{Results}

\section{Base Line Characteristics and Blood Biomarker Measurements}

As shown in Table 1, there were no significant differences among the 4 groups regarding age, sex, blood pressure, body weight, blood sugar and lipid profile. Leucocyte counts and concentrations of high-sensitivity CRP (hsCRP), MCP-1, RANTES and fractalkine in groups A and B were significantly higher than those in groups $\mathrm{C}$ and $\mathrm{D}$. However, there was no significant difference between groups A and B.

\section{QCA}

CAG studies demonstrated a total of 117 and 111 coronary stenotic lesions in the AMI and UAP groups, respectively, while in the SAP group there were 105 coronary lesions; 76 lesions $(65 \%)$ in the AMI, 77 lesions (69\%) in the UAP and 69 lesions (66\%) in the SAP group had stenosis $\geq 70 \%$. QCA results did not show significant differences regarding percent diameter stenosis and area stenosis among the AMI, UAP and SAP groups (Table 4).

\section{IVUS Measurements}

IVUS detected 117 plaques in group A, 111 plaques in group $\mathrm{B}$ and 105 plaques in group C. Patients in group $\mathrm{A}(51.3 \%)$ and group B (47.7\%) had more lipid plaques than those in group C (17.1\%) (all $\mathrm{P}<0.01$, respectively), while patients in group $\mathrm{C}$ had more fibrous plaques $(52.4 \%)$ than those in group A $(17.9 \%)$ and group B $(20.7 \%)(\mathrm{P}<0.01$, respectively). There were more ruptured plaques in groups $\mathrm{A}$ and $\mathrm{B}$ than those in group $\mathrm{C}(\mathrm{P}<0.01$, respectively). However, there was no significant difference between group $\mathrm{A}$ and group $\mathrm{B}$. There were more eccentric plaques in groups A and B, and the values of EEMA, $\mathrm{PA}, \mathrm{PB}$ and $\mathrm{RI}$ in groups $\mathrm{A}$ and $\mathrm{B}$ were significantly larger than those in group $\mathrm{C}(\mathrm{P}<0.05-0.01)$ (Table 3, Figure 1). 


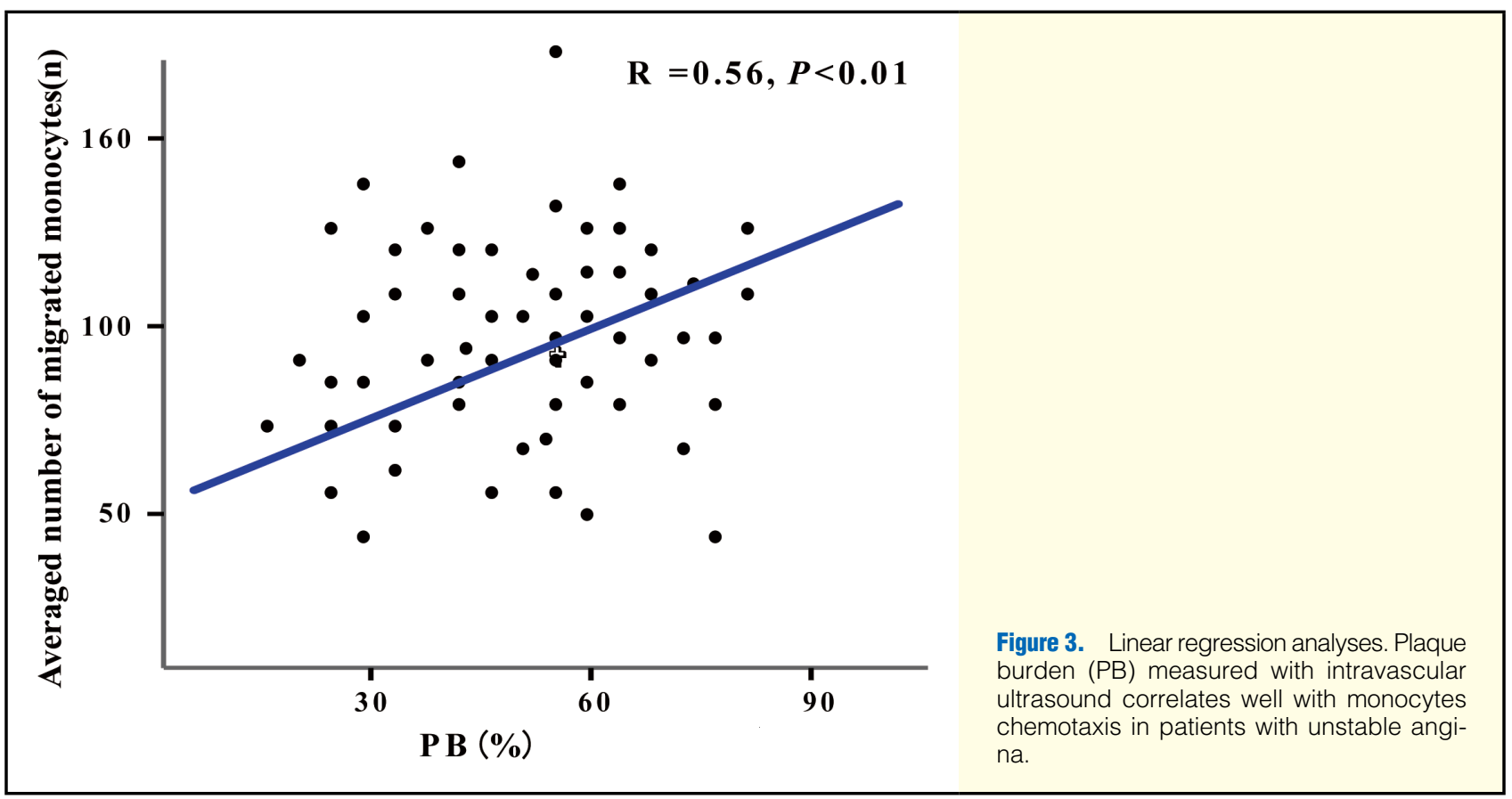

\begin{tabular}{lccc}
\hline \multicolumn{1}{c}{ Table 4. Measurements of Quantitative Coronary Angiography in $\mathbf{3}$ Patient Groups } & \\
\multicolumn{1}{c}{ Parameter } & Gr AMI $(\mathbf{n = 6 0})$ & UAP $(\mathbf{n = 6 0})$ & Gr SAP $(\mathbf{n}=\mathbf{6 0})$ \\
Percent diameter stenosis (\%) & $78.8 \pm 11.3$ & $76.8 \pm 9.1$ & $72.4 \pm 8.0$ \\
Percent area stenosis (\%) & $95.5 \pm 5.4$ & $94.6 \pm 5.2$ & $92.4 \pm 4.9$ \\
Culprit lesion length (mm) & $15.5 \pm 4.8$ & $18.0 \pm 5.0$ & $19.4 \pm 5.2$ \\
Reference lumen diameter (mm) & $3.1 \pm 0.40$ & $3.0 \pm 0.4$ & $3.0 \pm 0.4$ \\
Reference lumen area (mm²) & $7.3 \pm 1.9$ & $7.3 \pm 1.8$ & $7.3 \pm 1.9$ \\
\hline
\end{tabular}

Abbreviations as in Table 1.

\begin{tabular}{|c|c|c|c|c|}
\hline Parameter & Gr AMI $(n=60)$ & UAP $(n=60)$ & Gr SAP $(n=60)$ & Control $(n=40)$ \\
\hline MCP-1 & $41.4 \pm 9.3^{\star *,+\dagger}$ & $38.9 \pm 8.7^{* *,+\dagger}$ & $25.0 \pm 7.1^{\dagger}$ & $12.5 \pm 4.4$ \\
\hline RANTES & $42.8 \pm 7.1^{\star *},+\dagger$ & $35.2 \pm 6.1^{\star},+\dagger$ & $23.4 \pm 5.2$ & $15.3 \pm 3.9$ \\
\hline Fractalkine & $37.7 \pm 6.1^{\star \star},+\dagger$ & $29.3 \pm 4.0^{*, \dagger}$ & $21.6 \pm 3.2$ & $19.1 \pm 2.2$ \\
\hline
\end{tabular}

${ }^{*} \mathrm{P}<0.05,{ }^{* *} \mathrm{P}<0.01$ vs. SAP; ${ }^{\mathrm{T}} \mathrm{P}<0.05,{ }^{\mathrm{t}} \mathrm{P}<0.01$ vs. Control. Abbreviations as in Table 1.

\section{Chemotaxis Test}

The averaged number of migrated monocytes measured in 10 high-power microscopic fields in groups $\mathrm{A}$ and $\mathrm{B}$ was more than that in group $\mathrm{C}(162 \pm 16,155 \pm 15$ vs. $46 \pm 9, \mathrm{P}<0.01$, respectively; Figure 2). The averaged distance traveled by monocytes measured in 10 high-power microscopic fields in groups $\mathrm{A}$ and $\mathrm{B}$ was longer than that in group $\mathrm{C}(117.8 \pm 17.9 \mu \mathrm{m}$, $113.3 \pm 16.1 \mu \mathrm{m}$ vs. $60.1 \pm 8.3 \mu \mathrm{m}, \mathrm{P}<0.05$, respectively). Results of linear regression analyses showed that PB measured with IVUS correlated well with monocyte chemotaxis in group B $(\mathrm{r}=0.56, \mathrm{P}<0.01$, Figure 3$)$.

\section{Real-Time RT-PCR}

The levels of mRNA expression of MCP-1, RANTES and fractalkine in groups $\mathrm{A}$ and $\mathrm{B}$ were significantly increased compared with groups $C$ and $D(P<0.05$, respectively). However, there was no significant difference between group A and B (Table 5).

\section{Discussion}

Atherosclerotic plaque rupture is the major cause of ACS and stable plaques may become vulnerable to rupture or erosion once they develop active inflammation. Inflammation has emerged as a crucial force driving the initiation and progression of atherosclerotic lesion formation. ${ }^{22,23}$ Accumulation of monocytes/macrophages has been noted in the intima of early atherosclerotic lesions and these inflammatory cells may promote progression of atherosclerosis by producing and releasing various cytokines and chemokines. Studies have demonstrated that the chemokines MCP-1, RANTES and fractalkine are potent activators and chemoattractant signals of inflammatory and vascular cells. ${ }^{6,9,12,24}$ In the present study, we have shown higher expressions of MCP-1, RANTES and fractalkine in patients with AMI or UAP. Our results demonstrate that MCP-1, RANTES and fractalkine independently partici- 
pate in the pathogenesis of plaque vulnerability and subsequent plaque rupture.

Once combined with its receptor CCR2, MCP-1 activates monocytes/macrophages by promoting leukocyte-endothelium binding and migration to sites of inflammation. MCP-1 as an upstream chemokine in the atherosclerotic inflammatory pathway has been consistently detected in human atherosclerotic lesions, as well as in animal models of atherosclerosis with dietary-induced hypercholesterolemia, and it is a logical reasoning that the intensive infiltration of macrophages into plaques with active inflammation is, to a large extent, due to the chemotactic effects of MCP-1. Aiello et al reported that MCP-1 accelerated atherosclerosis in apolipoprotein E-deficient mice and was extensively expressed in macrophages in atherosclerotic plaques. ${ }^{25} \mathrm{MCP}-1$-deficient mice also had less prominent aortic accumulation of macrophages, reflecting the relative paucity of MCP-1-derived monocyte chemoattraction. ${ }^{26}$ Gosling et al found that the absence of MCP-1 appeared to confer dramatic protection against macrophage recruitment and atherosclerotic lesion formation without affecting lipoprotein metabolism in MCP-1-deficient mice. ${ }^{27}$ Zhong et al in our laboratory found that dominant-negative mutation of MCP-1 prevented vulnerable plaques from rupture in rabbits, independent of serum lipid levels. ${ }^{6}$

The CC chemokine RANTES and its receptors CCR1 and CCR5 in atherosclerosis have been addressed in a number of studies. RANTES has been implicated in cardiac inflammatory disorders after organ transplantation or arterial injury. In addition, RANTES has been detected in plasma samples of patients suffering from coronary heart disease. Mice deficient in the RANTES gene show impaired recruitment of $\mathrm{T}$ cells and monocytes to inflammatory foci. ${ }^{28}$ Barcelos et al found that antagonism of RANTES receptors with Met-RANTES reduced atherosclerotic plaque formation in mice. ${ }^{29}$ Braunersreuther et al reported that RANTES plays a central role in promoting late-stage atherosclerosis in the context of accelerated atherosclerosis in $\mathrm{ApoE}^{-/-}$mice promoted by high-fat diet. ${ }^{30}$

Fractalkine (CX3CL1) is a unique member of the CX3C chemokine subfamily. Accumulating evidence indicates CX3CL1/ CX3CR1 involvement in the pathogenesis of atherosclerosis. ${ }^{31,32}$ Teupser et al reported that the targeted deletion of CX3CL1 decreased atherosclerotic lesion formation in the brachiocephalic artery but not the aortic root, with fewer macrophages in the lesion area of atherosclerosis in $\mathrm{CX}_{3} \mathrm{CL1}^{-/} \mathrm{ApoE}^{-/-}$ mice, implicating a role of this chemokine system in atherogenesis. ${ }^{33}$ Furthermore, Lucas et al found expression of CX3CL1 and $\mathrm{CX} 3 \mathrm{CR} 1$ in human coronary atherosclerotic plaques, and that CX3CL1/CX3CR1 may contribute to atherogenesis and plaque destabilization in human coronary artery disease. ${ }^{34}$ Cheng et al found that blockade of CX3CL1 inhibited plaque growth and resulted in striking differences in plaque composition in low shear stress regions of the carotid arteries. ${ }^{35}$

Studies have also shown that MCP-1, RANTES and fractalkine play independent roles in atherogenesis. Digby et al reported that the anti-inflammatory effects of nicotinic acid in adipocytes contribute to its suppression of fractalkine, RANTES, and MCP-1 and upregulation of adiponectin. ${ }^{36}$ Saederup et al reported that fractalkine deficiency markedly reduced macrophage accumulation and atherosclerotic lesion formation in $\mathrm{CCR}^{-/-}$mice, providing the first in vivo evidence of independent roles for CX3CL1 and CCR2 in direct monocyte recruitment to atherosclerotic lesions. ${ }^{37}$ Combined inhibition of CCL2, CCR5, and CX3CR1 in ApoE ${ }^{-/-}$mice abrogated bone marrow monocytosis and additively reduced circulating monocytes and atherosclerosis, despite persistent hypercholesterolemia. More- over, the inhibition of CCL2, CX3CR1, and CCR5 in ApoE ${ }^{-/-}$ mice almost abolished atherosclerosis, suggesting that CX3CR1-, CCL2-, and CCR5-mediated signals play independent and additive roles in atherogenesis. ${ }^{24}$

Many investigators have reported that certain inflammatory markers, such as hsCRP, have the potential to predict the risk of future cardiovascular events. ${ }^{38,39}$ Liuzzo et al found that elevated CRP concentration $(>3 \mathrm{mg} / \mathrm{L})$ at the time of hospital admission predicted a poor outcome in patients with UAP. ${ }^{40} \mathrm{In}$ the present study, we found that the hsCRP, MCP-1, RANTES and fractalkine levels were significantly higher in patients with AMI and UAP than in patients with SAP, suggesting that serum levels of MCP-1, RANTES and fractalkine may be good markers of plaque vulnerability.

In the present study, we tested the monocyte chemotaxis in patients with ACS and found that the averaged number of migrated monocytes and the averaged distance traveled by monocytes in patients with AMI or UAP were higher than those of SAP patients, which reflects the close association of monocyte chemotaxis with the vulnerability of atherosclerotic plaques.

In order to show the expression levels of MCP-1, RANTES and fractalkine that modulate monocyte chemotaxis, we measured their mRNA expression levels in the monocytes of patients with ACS or SAP and found that mRNA expression levels of MCP-1, RANTES and fractalkine were higher in patients with ACS than in those with SAP. All these results reveal that MCP-1, RANTES and fractalkine are the main chemokines contributing to atherosclerotic plaque vulnerability.

Among the many plaque imaging techniques, IVUS has been advocated as assessing the morphological changes of vulnerable plaque in vivo. ${ }^{18,19,41-43}$ Our current study clearly demonstrated that patients with AMI or UAP have more vulnerable plaques characterized by a more eccentric distribution, a larger EEM area, a bigger PA and a larger PB. Correlation analysis found that PB measured with IVUS correlated well with monocyte chemotaxis, implying a role of monocytes chemotaxis and the related chemokines MCP-1, RANTES and fractalkine in the development of atherosclerotic plaques.

In conclusion, MCP-1, RANTES and fractalkine independently participate in the pathogenesis of coronary plaque vulnerability and subsequent plaque rupture.

\section{Acknowledgments}

This work was supported by the National Natural Science Foundation of China (No. 30871040, No. 30971216, No. 60971023) and grants from the Natural Science Foundation of Shandong Province (Y2008C17, 2009ZRA01110).

\section{References}

1. Burke AP, Farb A, Malcom GT, Liang YH, Smialek J, Virmani R. Coronary risk factors and plaque morphology in men with coronary disease who died suddenly. N Engl J Med 1997; 336: 1276-1282.

2. Davies MJ. The pathophysiology of acute coronary syndromes. Heart 2000; 83: $361-366$.

3. Bursill CA, Channon KM, Greaves DR. The role of chemokines in atherosclerosis: Recent evidence from experimental models and population genetics. Curr Opin Lipidol 2004; 15: 145-149.

4. Zernecke A, Shagdarsuren E, Weber C. Chemokines in atherosclerosis: An update. Arterioscler Thromb Vasc Biol 2008; 28: 1897-1908.

5. Charo IF, Ransohoff RM. The many roles of chemokines and chemokine receptors in inflammation. N Engl J Med 2006; 354: 610621.

6. Zhong L, Chen WQ, Ji XP, Zhang M, Zhao YX, Yao GH, et al. Dominant-negative mutation of monocyte chemoattractant protein-1 prevents vulnerable plaques from rupture in rabbits independent of serum lipid levels. J Cell Mol Med 2008; 12: 2362-2371.

7. Mori E, Komori K, Yamaoka T, Tanii M, Kataoka C, Takeshita A, et al. Essential role of monocyte chemoattractant protein-1 in development of restenotic changes (neointimal hyperplasia and constric- 
tive remodeling) after balloon angioplasty in hypercholesterolemic rabbits. Circulation 2002; 105: 2905-2910.

8. Yla-Herttuala S, Lipton BA, Rosenfeld ME, Sarkioja T, Yoshimura $\mathrm{T}$, Leonard EJ, et al. Expression of monocyte chemoattractant protein 1 in macrophage-rich areas of human and rabbit atherosclerotic lesions. Proc Natl Acad Sci USA 1991; 88: 5252-5256.

9. Sun W, Wang G, Zhang ZM, Zeng XK, Wang X. Chemokine RANTES is upregulated in monocytes from patients with hyperhomocysteinemia. Acta Pharmacol Sin 2005; 26: 1317-1321.

10. Veillard NR, Kwak B, Pelli G, Mulhaupt F, James RW, Proudfoot AE, et al. Antagonism of RANTES receptors reduces atherosclerotic plaque formation in mice. Circ Res 2004; 94: 253-261.

11. Jones KL, Maguire JJ, Davenport AP. Chemokine receptor CCR5: From AIDS to atherosclerosis. Br J Pharmacol 2010; 162: $1453-$ 1469.

12. Damås JK, Boullier A, Waehre T, Smith C, Sandberg WJ, Green S, et al. Expression of fractalkine (CX3CL1) and its receptor, CX3CR1, is elevated in coronary artery disease and is reduced during statin therapy. Arterioscler Thromb Vasc Biol 2005; 25: 2567-2572.

13. Combadière C, Potteaux S, Gao JL, Esposito B, Casanova S, Lee EJ, et al. Decreased atherosclerotic lesion formation in CX3CR1/apolipoprotein E double knockout mice. Circulation 2003; 107: 10091016.

14. McDermott DH, Fong AM, Yang Q, Sechler JM, Cupples LA, Merrell MN, et al. Chemokine receptor mutant CX3CR1-M280 has impaired adhesive function and correlates with protection from cardiovascular disease in humans. J Clin Invest 2003; 111: 1241-1250.

15. Fraker TD Jr, Fihn SD, Gibbons RJ, Abrams J, Chatterjee K, Daley J, et al; American College of Cardiology; American Heart Association; American College of Cardiology/American Heart Association Task Force on Practice Guidelines Writing Group. 2007 chronic angina focused update of the ACC/AHA 2002 Guidelines for the management of patients with chronic stable angina: A report of the American College of Cardiology/American Heart Association Task Force on Practice Guidelines Writing Group to develop the focused update of the 2002 Guidelines for the management of patients with chronic stable angina. Circulation 2007; 116: 2762-2772.

16. Anderson JL, Adams CD, Antman EM, Bridges CR, Califf RM, Casey DE Jr, et al; American College of Cardiology; American Heart Association Task Force on Practice Guidelines (Writing Committee to Revise the 2002 Guidelines for the Management of Patients With Unstable Angina/Non-ST-Elevation Myocardial Infarction); American College of Emergency Physicians; Society for Cardiovascular Angiography and Interventions; Society of Thoracic Surgeons; American Association of Cardiovascular and Pulmonary Rehabilitation; Society for Academic Emergency Medicine. ACC/AHA 2007 guidelines for the management of patients with unstable angina/non-ST-Elevation myocardial infarction: A report of the American College of Cardiology/American Heart Association Task Force on Practice Guidelines (Writing Committee to Revise the 2002 Guidelines for the Management of Patients With Unstable Angina/Non-ST-Elevation Myocardial Infarction) developed in collaboration with the American College of Emergency Physicians, the Society for Cardiovascular Angiography and Interventions, and the Society of Thoracic Surgeons endorsed by the American Association of Cardiovascular and Pulmonary Rehabilitation and the Society for Academic Emergency Medicine. J Am Coll Cardiol 2007; 50: e1 -e157.

17. Mintz GS, Nissen SE, Anderson WD, Rosenfield K, Bailey S, Siegel $\mathrm{R}$, et al. American College of Cardiology Clinical Expert Consensus Document on standards for acquisition, measurement and reporting of intravascular ultrasound studies (IVUS). J Am Coll Cardiol 2001; 37: $1478-1492$.

18. Chen WQ, Zhang L, Liu YF, Chen L, Ji XP, Zhang M, et al. Prediction of atherosclerotic plaque ruptures with high frequency ultrasound imaging and serum inflammatory markers. Am J Physiol Heart Circ Physiol 2007; 293: H2836-H2844.

19. Chen WQ, Zhang M, Ji XP, Ding SF, Zhao YX, Chen YG, et al. Usefulness of high frequency vascular ultrasound imaging and serum inflammatory markers to predict plaque rupture in patients with stable and unstable angina pectoris. Am J Cardiol 2007; 100: $1341-$ 1346.

20. Wang GP, Deng ZD, Ni J, Qu ZL. Oxidized low density lipoprotein and very low density lipoprotein enhance expression of monocyte chemoattractant protein-1 in rabbit peritoneal exudate macrophages. Atherosclerosis 1997; 133: 31-36.

21. Livak KJ, Schmittgen TD. Analysis of relative gene expression data using real-time quantitative PCR and the 2(-delta delta $\mathrm{C}(\mathrm{T})$ ) method. Methods 2001; 25: 402-408.

22. Li L, Cai XJ, Feng M, Rong YY, Zhang Y, Zhang M. Effect of adiponectin overexpression on stability of preexisting plaques by induc- ing prolyl-4-hydroxylase expression. Circ J 2010; 74: 552-559.

23. Li ZY, Tang TY, Jiang F, Zhang Y, Gillard JH. Reduction in arterial wall strain with aggressive lipid-lowering therapy in patients with carotid artery disease. Circ J 2011; 75: 1486-1492.

24. Combadière C, Potteaux S, Rodero M, Simon T, Pezard A, Esposito $\mathrm{B}$, et al. Combined inhibition of CCL2, CX3CR1, and CCR5 abrogates Ly6C(hi) and Ly6C(lo) monocytosis and almost abolishes atherosclerosis in hypercholesterolemic mice. Circulation 2008; 117: $1649-1657$.

25. Aiello RJ, Bourassa PA, Lindsey S, Weng W, Natoli E, Rollins BJ, et al. Monocyte chemoattractant protein-1 accelerates atherosclerosis in apolipoprotein E-deficient mice. Arterioscler Thromb Vasc Biol 1999; 19: $1518-1525$.

26. Gu L, Okada Y, Clinton SK, Gerard C, Sukhova GK, Libby P, et al. Absence of monocyte chemoattractant protein-1 reduces atherosclerosis in low density lipoprotein receptor-deficient mice. Mol Cell 1998; 2: 275-281.

27. Gosling J, Slaymaker S, Gu L, Tseng S, Zlot CH, Young SG, et al. $\mathrm{MCP}-1$ deficiency reduces susceptibility to atherosclerosis in mice that overexpress human apolipoprotein B. J Clin Invest 1999; 103: $773-778$.

28. Zernecke A, Liehn EA, Gao JL, Kuziel WA, Murphy PM, Weber C. Deficiency in CCR5 but not CCR1 protects against neointima formation in atherosclerosis-prone mice: Involvement of IL-10. Blood 2006; 107: 4240-4243.

29. Barcelos LS, Coelho AM, Russo RC, Guabiraba R, Souza AL, BrunoLima G Jr, et al. Role of the chemokines CCL3/MIP-1 alpha and CCL5/RANTES in sponge-induced inflammatory angiogenesis in mice. Microvasc Res 2009; 78: 148-154.

30. Braunersreuther V, Zernecke A, Arnaud C, Liehn EA, Steffens S, Shagdarsuren E, et al. Ccr5 but not Ccr1 deficiency reduces development of diet-induced atherosclerosis in mice. Arterioscler Thromb Vasc Biol 2007; 27: 373-379.

31. Liu H, Jiang D. Fractalkine/CX3CR1 and atherosclerosis. Clin Chim Acta 2011; 412: 1180-1186.

32. Jones BA, Beamer M, Ahmed S. Fractalkine/CX3CL1: A potential new target for inflammatory diseases. Mol Interv 2010; 10: 263-270.

33. Teupser D, Pavlides S, Tan M, Gutierrez-Ramos JC, Kolbeck R, Breslow JL. Major reduction of atherosclerosis in fractalkine (CX3CL1)-deficient mice is at the brachiocephalic artery, not the aortic root. Proc Natl Acad Sci USA 2004; 101: 17795-17800.

34. Lucas AD, Bursill C, Guzik TJ, Sadowski J, Channon KM, Greaves DR. Smooth muscle cells in human atherosclerotic plaques express the fractalkine receptor CX3CR1 and undergo chemotaxis to the CX3C chemokine fractalkine (CX3CL1). Circulation 2003; 108: $2498-2504$.

35. Cheng C, Tempel D, van Haperen R, de Boer HC, Segers D, Huisman $\mathrm{M}$, et al. Shear stress-induced changes in atherosclerotic plaque composition are modulated by chemokines. J Clin Invest 2007; 117: 616-626.

36. Digby JE, McNeill E, Dyar OJ, Lam V, Greaves DR, Choudhury RP. Anti-inflammatory effects of nicotinic acid in adipocytes demonstrated by suppression of fractalkine, RANTES, and MCP-1 and upregulation of adiponectin. Atherosclerosis 2010; 209: 89-95.

37. Saederup N, Chan L, Lira SA, Charo IF. Fractalkine deficiency markedly reduces macrophage accumulation and atherosclerotic lesion formation in CCR2-I- mice: Evidence for independent chemokine functions in atherogenesis. Circulation 2008; 117: $1642-1648$.

38. Avanzas P, Arroyo-Espliguero R. Markers of inflammation and multiple complex stenoses (pancoronary plaque vulnerability) in patients with non-ST segment elevation acute coronary syndromes. Heart 2004; 90: 847-852.

39. Haim M, Tanne D, Boyko V, Reshef T, Goldbourt U, Leor J, et al. Soluble intercellular adhesion molecule-1 and long-term risk of acute coronary events in patients with chronic coronary heart disease. $\mathrm{J} \mathrm{Am}$ Coll Cardiol 2002; 39: 1133-1138.

40. Liuzzo G, Biasucci LM, Gallimore JR, Grillo RL, Rebuzzi AG, Pepys $\mathrm{MB}$, et al. The prognostic value of $\mathrm{C}$-reactive protein and serum amyloid A in severe unstable angina. $N$ Engl J Med 1994; 331: 417-424.

41. Frimerman A, Miller HI, Hallman M, Laniado S, Keren G. Intravascular ultrasound ultrasound characterization of thrombi of different composition. Am J Cardiol 1994; 73: 1053-1057.

42. Ge J, Chirillo F, Schwedtmann J, Görge G, Haude M, Baumgart D, et al. Screening of ruptured plaques in patients with coronary artery disease by intravascular ultrasound. Heart 1999; 81: 621-627.

43. von Birgelen C, Klinkhart W, Mintz GS, Papatheodorou A, Herrmann $\mathrm{J}$, Baumgart D, et al. Plaque distribution and vascular remodeling of ruptured and non-ruptured coronary plaques in the same vessel: An intravascular ultrasound study in vivo. J Am Coll Cardiol 2001; 37: $1864-1870$ 